\title{
COMMUNITY PHARMACIST LED MEDICATION REVIEWS IN THE UK: A SCOPING REVIEW OF THE MEDICINES USE REVIEW AND THE NEW MEDICINE SERVICE LITERATURES
}

Duncan Stewart, Cate Whittlesea, Ranjita Dhital, Louise Newbould, Jim McCambridge

DOI: 10.1016/j.sapharm.2019.04.010

\section{INTRODUCTION}

Medication reviews are intended to improve the quality, safety and appropriate use of medicines ${ }^{1}$. There is an extensive international literature to demonstrate the effectiveness of pharmacist delivered medication reviews. For example, reduced health problems, increased medication adherence and quality of life are reported consistently in systematic reviews ${ }^{2,3}$. Interpreting the findings of these reviews in relation to the specific context of UK community pharmacy is challenging. Differences in terminology and service configurations across countries are apparent, and meta-analyses often include pharmacist interventions from a mix of clinical settings and do not present effect sizes for community pharmacies alone ${ }^{2,3}$. There is also a large degree of heterogeneity in intervention content and delivery models within and across countries ${ }^{3}$, including Medicines Therapy Management services in the $\mathrm{US}^{4}$ and Home Medication Review in Australia ${ }^{5}$ which have similarities to UK pharmacy-led medicines review services.

Since 2005 all community pharmacists in the UK are contracted by the NHS to deliver essential services (such as dispensing). A second tier of 'advanced' contracted services includes Medicines Use Reviews (MURs) and the New Medicine Service (NMS), requiring community pharmacists who chose to deliver them to be appropriately trained and to meet specified service requirements ${ }^{6}$; these services are free to patients. Remuneration for contracted pharmacies from the NHS is $£ 28$ per MUR, up to a maximum of 400 per year, and up to $£ 28$ per NMS depending on numbers completed ${ }^{7}$. The purposes of MURs are to improve patients' understanding of their medicines and adherence, particularly among those with chronic conditions, highlight problematic side effects and propose solutions where appropriate, and to reduce medicines wastage ${ }^{8}$. The NMS supports people with long-term conditions and newly prescribed medication improve their medicines adherence, and there is also an explicit aim for the NMS to support patients make decisions about their treatment and self-management ${ }^{9}$. Most trials and other evaluation studies typically examine medication reviews for specific health conditions. Studies of medication reviews, of the types delivered by UK community pharmacists, which could include medicines for a range of conditions, are much less common. Thus, in one review, only five studies (4 RCTs and 1 prospective cohort study) were 
classified as MUR type adherence reviews delivered in a pharmacy, and most interventions included were disease specific ${ }^{3}$.

Extending the community pharmacist role in the UK beyond traditional dispensing is valued as an opportunity to demonstrate the worth, and further develop the skills, of the profession ${ }^{10}$. Among patients, the range of pharmacists' skills and training can be under-appreciated, to the extent that this can be a barrier to discussion of health behaviours ${ }^{11}$. Some qualitative studies report that patients' perceptions of pharmacists as appropriately skilled to provide medicines related information and care are influenced positively by having already experienced medication reviews ${ }^{10}$. Much hinges on individual pharmacist's communication and interpersonal skills, which are noted to be a source of variability in the conduct of medication reviews ${ }^{10}$. It is, therefore, not surprising that skills in behaviour change and communication strategies are identified as training needs ${ }^{10,12}$, particularly for longer qualified pharmacists whose training predates attempts to increase attention to these elements ${ }^{12}$.

Community pharmacies offer a range of public health services, including sexual health screening, smoking cessation and alcohol interventions ${ }^{13}$. Delivery of these services during the course of routine NHS contacts is encouraged ${ }^{14}$ and community pharmacies are well placed to provide them ${ }^{15}$; current MUR/NMS service specifications require pharmacists to ask patients about these and document any advice given. A systematic review of community pharmacist views found broad support for an increased public health role, but training needs and lack of confidence in how to intervene to support health behaviour change were also reported ${ }^{16}$. Medication reviews provide valuable opportunities to discuss with patients the possible consequences of specific behaviours for the effectiveness of medications, and for their health more generally. Potentially, this could be more comprehensive, and use more sophisticated methods, than the 'advice giving' associated with dispensing related interactions with patients ${ }^{17}$. This is congruent with General Pharmaceutical Council practice standards that place the interests and perspectives of the patient at the heart of patient consultations ${ }^{18}$. Informed by the Medication Related Consultation Framework (MRCF) ${ }^{19}$, these standards detail how pharmacists can use core skills to make their consultations about medications more patient-centred. The expectation is that all pharmacists are working towards, or have achieved, the required consultation skills which underpin these standards ${ }^{20}$.

This aim of this scoping review was to identify and examine existing empirical evidence in peerreviewed journals relating to MUR and NMS consultations delivered by community pharmacists in the UK. Objectives were to: (1) identify and summarise the findings of existing MUR and NMS studies; (2) examine key features of these services, including barriers and facilitators to 
implementation (3) identify limitations and gaps in this literature; (4) identify any policy and practice implications based on existing findings.

\section{METHOD}

We used systematic searches to identify and map all of the available MUR and NMS empirical literature in a scoping review. Within this mapping exercise, we sought data on the conduct of MUR and NMS consultations, the perceptions of pharmacists and patients, and the outcomes of consultations.

\section{Inclusion and exclusion criteria}

Searches of primary research studies published in journal articles between 2005 (when MURs were introduced; the NMS was introduced in 2011) and May 2018 were conducted in MEDLINE, PycINFO, Embase and Scopus databases, selected to achieve broad coverage of the review topic. Searches were limited to empirical studies with at least some data specific to these services. Reviews, articles with no primary data, and studies of similar non-UK services were excluded. No restrictions on study design were applied.

\section{Search strategy}

Search terms for each database were 'medicine* use review', 'MUR', 'new medicine service' and 'NMS'. Titles and abstracts of papers for potential inclusion were screened independently by two co-authors (DS \& LN). Disagreements or uncertainties about specific papers were resolved by discussion with a third co-author (JM). Reference lists of identified articles relevant to the review but rejected because of exclusion criteria, and reference lists of included articles, were manually searched for additional eligible studies.

\section{Extraction and analysis}

An Excel data extraction form was used to record year of publication, type of services delivered, study objectives, design and methodology, sample type and size, data collection time frame, and key study quantitative and/or qualitative findings. Systematic mapping of extracted data against these headings was conducted by one co-author (DS), and the content checked by the other co-authors. A narrative synthesis was undertaken to meet the study objectives. As a scoping review, the quality of studies was not evaluated formally.

\section{RESULTS}


A total of 461 articles were identified through database searching, and an additional 6 from hand searches (Figure 1). After removal of duplicates, 141 titles and abstracts were screened, from which 46 full text papers were assessed for eligibility. Five studies were excluded: no empirical data $(n=3)$; not MUR/NMS ( $n=1)$; a study of recruitment difficulties to a feasibility study already included in this review $(n=1)$. Of the 41 papers included in the review, 28 were of MURs, 10 of NMS and 3 for both services.

The characteristics of the 41 MUR and NMS papers are described in Tables 1-5. Few studies employed an RCT or quasi-experimental design: one study (two papers examining effectiveness and cost-effectiveness) was an $\mathrm{RCT}^{21,22}$, one was a small (randomised) feasibility study ${ }^{23}$, and another recruited a non-randomised control group ${ }^{24}$. Three papers exclusively examined secondary data from pharmacy records ${ }^{25-27}$. A further five mixed methods studies used secondary data in combination with other (mainly qualitative) data collection ${ }^{28-32}$. The remainder of papers were from qualitative studies ( $n=14$ ), including four papers from the same study ${ }^{17,33-35}$, and from surveys $(n=15)$.

\section{Barriers and facilitators to implementation}

A number of studies concluded that health system factors contribute to variable levels of integration of MURs into routine patient care. In particular, studies using observation of consultations, interviews and surveys identified lack of communication and collaboration between community pharmacists and GPs ${ }^{29,33,36}$ as a barrier to implementation and thus limiting the potential benefit to patients. Similarly, poorly developed relationships with GPs identified though observation and interviews ${ }^{37,38}$ and perceived lack of interest and awareness (from interviews and focus groups) by $\mathrm{GPS}^{39,40}$ have been reported to impede implementation of the (more recent) NMS.

The organisational setting of the pharmacy is an important factor facilitating the uptake of MURs, with experiences differing by pharmacy type. There is evidence for contrasting approaches to enhanced services in multiples and independents ${ }^{25,28,29,41}$, confirmed by analysis of national MUR data showing more extensive adoption in the former ${ }^{30}$, perhaps driven by internal company pressures to achieve MUR targets ${ }^{42}$. A retrospective study of pharmacy records found significantly more patients per pharmacy were seen for targeted respiratory MURs in Healthy Living Pharmacies 31. The numbers of MURs performed by pharmacists varies ${ }^{32}$ and appears to be affected by the pharmacists' working hours and whether store based rather than locum pharmacists ${ }^{43}$. Availability of a consultation area suitable for performing MURs and pharmacists having sufficient time available to perform them are also identified as influencing the number of MURs conducted ${ }^{43}$. 
Some patient groups have more limited access to medication consultations, including the elderly ${ }^{44}$, and one survey found limited uptake in a rural community ${ }^{45}$.Perceived difficulties taking consent have been cited by pharmacists as the main reason for not undertaking MURs or the NMS with young people and/or their carers ${ }^{46}$. More generally, one study reported that pharmacists avoid more complex cases (for example, with multiple conditions) because they were judged to be more difficult to recruit and would take more time to complete ${ }^{33}$. Patients from marginalised communities (e.g. people with disabilities, diagnosed with a serious mental illness, or with no fixed abode) are not always aware of enhanced pharmacy services but would welcome greater engagement, while pharmacists find it more difficult to identify, communicate with and accommodate the specific needs of these patients within the context of the busy pharmacy environment ${ }^{47}$.

\section{Patient perceptions}

Patients' perceptions of MURs and NMS are broadly positive ${ }^{34,48}$. A survey of over 500 patients following an MUR (although the response rate was very low; 24\%) found high levels of patient satisfaction with the service across a number of domains, even if some patients were initially reluctant to take part in a MUR ${ }^{49}$. Patients have reported learning more about their medicines and side effects after a MUR, and to have improved their compliance ${ }^{32,50}$. More detailed examination of patient experiences using observation of MURs and patient interviews indicated that although patients appreciate the opportunity to discuss medication with a pharmacist, MUR consultations do not necessarily improve their knowledge of medicines or affect how they used them ${ }^{34}$. Patients have been found to value the two way dialogue with pharmacists and be able to ask questions ${ }^{51}$. Misalignment between patients' and pharmacists' framing of the purpose and potential benefits of the NMS has also been reported ${ }^{52}$, as well as variations in the information available to patients about the nature of pharmacist-patient roles ${ }^{53}$. More general expectations of these services among pharmacists and the public have been found to be similarly high to each other ${ }^{48}$.

\section{Pharmacist perceptions}

Overall, community pharmacists are positive about the idea of MUR and NMS services, and view them as an opportunity to use their skills. Studies report community pharmacists' confidence to undertake MURs to be high ${ }^{41,54}$ and perceive the service to be of value to patients ${ }^{43}$. Pharmacists appear to underestimate the willingness of patients compared to the general public to engage with enhanced pharmacy services ${ }^{48}$. One small survey found opinions differed as to whether MURs constitute a tick-box exercise ${ }^{55}$, but found agreement that MURs should strike a balance between clinical (e.g. ensuring patients take correct medication) and behavioural (e.g. using medication in the correct way) content. 
Despite pharmacists holding positive views about the potential value of the NMS ${ }^{40}$, reflections on practice suggest they are not convinced of its necessity for some patients. Qualitative evidence indicated that many consultations did not identify any problems with the patients' medicines, raising questions about targeting ${ }^{37}$. Thus, focus groups with community pharmacists have identified potential benefits of the NMS service, but opinions of implementing the NMS in practice are much more mixed ${ }^{38}$. Prior to the introduction of the NMS, payment structure, speed of implementation, and the availability of supporting materials were cited by pharmacists as potential barriers to implementation ${ }^{40}$. The influence of these or other environmental factors on practice has not been examined in more recent literature.

\section{Conduct of consultations}

The duration of these consultations is short. A survey of 341 pharmacists estimated MUR consultations to take an average of 10 minutes and the NMS an average of 12 minutes, durations which were found to be acceptable to both pharmacists and patients ${ }^{48}$. Ethnographic observations of 54 MUR consultations and interviews with 34 MUR patients and 5 pharmacists ${ }^{17}$ had a number of key findings. MUR consultations were brief and involved mainly closed questions to enable quick and easy completion of the MUR form; the MUR was often introduced as a quick check of medicines. Opportunities for patients to ask questions were minimised. Pharmacists were reluctant to engage in discussion of patients' illnesses, which patients often raised. Thus, the consultations did not address how patients might manage their illness better with their medicines, and had little impact on medicine use. From this study, it is doubtful that the depth of engagement with patients and their health problems during consultations is sufficient to fulfil the purposes of MURs beyond checking safety. Pragmatic constraints of workload and pharmacy organisation were reported by pharmacists as barriers to effective MUR implementation.

In contrast, one small observational study of MUR consultations $(n=7)$ reported that patients valued discussion with the pharmacist, when it involved an exchange of information rather than simply information giving ${ }^{56}$. Similarly, standardised documentation for MURs may not constrain pharmacists' autonomy to adapt the material, to avoid a formulaic approach to medication discussions ${ }^{42}$. MUR quality indicators have been proposed to improve recording of consultations having been delivered ${ }^{57}$.

Concern has been expressed that opportunities for NMS consultations are more limited than originally intended ${ }^{26}$. This is supported by a pharmacist survey that found low levels of NMS provision for patients prescribed oral anti-coagulants for stroke prevention in atrial fibrillation ${ }^{58}$. Observations and interviews with patients suggest NMS consultations to be a pharmacist led 
questioning of the patient, with variation in the extent to which pharmacists keep to a formal NMS discussion schedule ${ }^{52}$. Focus groups with pharmacists before NMS implementation identified interview techniques and communication skills as being important for the successful delivery of NMS but not something requiring further training ${ }^{40}$. Pharmacists also had positive attitudes to providing the service, seeing it as an opportunity to use their clinical skills to benefit patients. In practice, the importance of pharmacists' communication and interpersonal skills is underlined by the pragmatic approaches taken to implementing medication reviews. An observational study of NMS delivery reported pharmacists using strategies to persuade patients to have NMS and attempting to keep an informal tone to discussions ${ }^{37}$. The NMS question guide was thus adapted to suit conversation flow and pharmacists' perceptions of the purpose of NMS. Whilst some managed patient discussions competently, this study also found evidence that pharmacists needed to enhance their consultation and communication skills to ensure that NMS consultations are patient-centred. For example, some regarded NMS to be information giving, rather than exploring patient understanding of medication, calling into question how patient-centred the service delivered can be expected to be. Using a similar methodology Waring et al. reported that not all pharmacists were equally skilled at communicating with their patients during NMS consultations, with some more able to go 'off-script' to ask about lifestyle factors ${ }^{59}$. Significantly, these pharmacists tended to more experienced and concerned with developing a relationship with patients.

Very little information is available in the literature on the extent of discussion or advice on health behaviours during consultations. A pharmacist completed survey reported over a fifth of NMS patients received advice on such issues, most commonly on diet, with alcohol and smoking advice provided to around $40 \%$ of these patients ${ }^{60}$. Such shortcomings extend beyond the conduct of MURs and the NMS, indicating broader challenges to moving from a traditional community pharmacist role to consistent adoption of patient-centred approaches to practice. Interviews with 15 community pharmacists suggested a perception that cardiovascular disease patients may react negatively to the uninvited offer of health behaviour advice, and in turn made pharmacists reluctant to discuss broader issues of relevance to patients' health ${ }^{61}$. Some pharmacists in the sample felt that they did not receive appropriate skills training to offer patients such advice, although confidence to do this appeared to develop over time. Management of long term conditions has been described by pharmacists as identifying medication issues and informing/educating patients about it, rather than actively involving patients in decision making about their medication ${ }^{62}$. A more recent focus group and interview study ${ }^{63}$ with a range of pharmacists and staff, including 6 early career community pharmacists and 8 community pharmacy pre-registration tutors reinforced the need to avoid technical language during consultations, avoiding being overly friendly (pharmacists perceived this to 
be off-putting to patients) and flexibility to adapt communication style to individual patients. Thus, overly formalised interventions cannot facilitate patient centred care.

\section{Outcomes}

The majority of studies were qualitative or surveys and typically of small scale, and few studies evaluated outcomes of MURs or the NMS in any way. To date only one randomised trial (of NMS) has been conducted. This trial recruited 504 participants, allocated to NMS or usual care, and measured self-reported medication adherence at 10 weeks follow-up, defined as missing no doses without the advice of a medical professional in the previous 7 days ${ }^{21}$. NMS significantly increased the proportion of patients adhering to their new medicine by about $10 \%$, and was significant in intention to treat analyses and after adjustment for missing data. Economic modelling of adherence outcomes, using NHS and non-NHS resource use costs and costs of the intervention costs, found health benefit at lower cost attributable to NMS; a mean of 0.05 more QALYs per patient, at a mean reduced cost of $-f 144^{22}$. Although this was designed as a pragmatic trial, it is unclear how far these findings may generalise to the outcomes that may be expected when NMS is delivered in routine practice.

A range of outcomes have been reported by studies not robustly designed to identify outcomes. A quasi-experimental study of post-hospital counselling and community pharmacist MURs improved patients' knowledge of their medication, but was undermined by less than half of patients for whom a MUR was recommended actually receiving one ${ }^{24}$; the primary reason was patients having their medicine delivered to their home, and thus not requiring a visit to a community pharmacy. Lack of mobility has also been identified as a barrier to conducting post-hospital discharge MURs in a small feasibility trial ${ }^{23}$. In a large survey-based evaluation of hospital referrals to a community pharmacy follow-up service, MUR ( $n=288$ ) or NMS ( $n=241)$ consultations were the most common types of service provided (if provided at all), with results indicating that patients receiving a follow-up consultation (of any type) may have lower rates of readmission and shorter hospital stays ${ }^{27}$. A patient survey ( $n=232$, from 4 community pharmacies) found that those who had received an advanced pharmacy service, such as a MUR, reported greater medicines adherence and satisfaction with medicine related information ${ }^{64}$. There may be unintended consequences to pharmacists spending time undertaking these consultations: support-staff report feeling frustrated when left to explain to patients that the pharmacist is not available because they are conducting an MUR ${ }^{35}$.

\section{DISCUSSION}

The MUR and NMS literature largely focuses on the introduction and early implementation of these services, with little detailed attention to process and outcomes for patients. The international 
literature of pharmacist- led medication reviews convincingly shows improved disease-specific and medication adherence outcomes ${ }^{2}$, but beyond the single NMS RCT ${ }^{21}$ the effectiveness of UK medication related advanced services has not been evaluated, despite on-going challenges to successful implementation ${ }^{65}$. Confidence that the specific aims of MUR and NMS consultations ${ }^{8,9}$ will be achieved in practice is, therefore, limited by the research evidence available.

There is enthusiasm for MURs and the NMS from both pharmacists and patients as a means to improve the way medication is taken, and by implication effectiveness and safety ${ }^{34,38,41,43,48-50,55}$. In practice, discussions of medicines appear to often involve one-way communication of information from pharmacists to patients ${ }^{17,37,52}$, described previously as an 'educator/informer' role ${ }^{10}$, with limited exploration of patient perspectives or attempt to gain the broader understanding of patient circumstances ${ }^{17,33,34,59}$ that should be expected to provide secure foundations for consultation practice ${ }^{18}$. There is scant information in the literature about how community pharmacists perceive implementation of these services to have changed or developed their practice, or how they may benefit patients. Similarly, very little is known about patients' perspectives of whether and how medicine consultations influence their own behaviour. These are essential elements to better understanding mechanisms that underpin delivery and outcomes of medication reviews, and could usefully inform future advances in UK community pharmacy practice.

Development and roll-out of consultations skills training for pharmacists ${ }^{66}$ occurred in 2014, after the introduction of MURs and the NMS. In such circumstances it might be expected that the conduct of the services reported in earlier studies does not reflect practice standards aspirations. Pharmacists' skills in behaviour change and in communication have been identified as training needs 10,12 , particularly for longer qualified pharmacists whose training predates attempts to increase attention to these elements ${ }^{12}$. Turning person-centred rhetoric into tangible experiences of the delivery of medication reviews involves supporting pharmacists to engage with patients as active participants in decision making and ensuring that any information and advice offered is meaningful and appropriate to their needs ${ }^{67,68}$. Future initiatives will also need to account for external factors that influence what happens in consultations, beyond the control of individual community pharmacists, including the organisational cultures of different types of pharmacy, funding structures and targets, constraints on pharmacists' time and relationships with GPs. Secondary analysis of data published after the searches for this review were completed shows that implementation of the NMS can be achieved with minimal impact on GP services ${ }^{69}$. 
Examples of more person-centred practice can be found in the literature $37,42,55,56,59$ and include: (a) avoiding using consultations as a medicine checking exercise; (b) adopting a flexible and informal communication style; (c) asking open questions; (d) exploring issues relevant to patients' condition(s); (e) checking patient understanding of issues raised in consultations; (f) using consultations to build relationships. Some pharmacists are skilled at adapting the standardised discussion schedules to the individual circumstances of the patient ${ }^{37,42}$. Greater experience may be a factor ${ }^{59}$, but the reasons for such varied practice and identification of mechanisms to improve it require further research and elaboration.

Pharmacists typically view addressing patient's broader health as important and a legitimate part of their role, but secondary to medicine related issues ${ }^{16}$. A range of barriers to pharmacists raising and discussing lifestyle factors have been identified by previous international reviews, including lack of time, low confidence, insufficient skills, lack of demand, and perceptions among pharmacists that patients may react negatively to unwanted advice ${ }^{16,70}$. Thus attention to medication use unsurprisingly lies at the heart of medicines consultations. Recognising the public health potential of community pharmacies, the Healthy Living Pharmacy framework, encompassing workforce development, improving premises and community engagement, was introduced to foster health promotion activities after successful piloting ${ }^{31}$. The impact of this initiative on the delivery of medication consultations, and on the barriers to person-centred practice identified above, has yet to be examined. Evidence from this review indicates that attention to health behaviours is often not included in medication consultations, or is considered incidental to the primary purposes of the service provision.

Improving the quality of life and care for the rising numbers of people with long term conditions is a UK policy priority ${ }^{14,71,72}$. This presents opportunities for pharmacists to play a major role in improving the health and wellbeing of this population, including optimising the contributions of routine pharmacy services such as medication reviews. There is untapped potential in utilising existing medication review consultations to address patient agendas in the manner proposed by the policy documents and in the training materials developed for community pharmacists.

There are some limitations to this review. Although we aimed to map the existing MUR and NMS literature, we chose to limit our searches to empirical data in peer reviewed journals; grey literature searches may have identified further information about these services. Nevertheless, our inclusion criteria were broad and identified studies with a diverse range of methodologies. This proved useful in highlighting significant gaps in the available evidence, but limited meaningful comparisons between studies. As a scoping review, the quality of included studies was not evaluated formally. 


\section{Conclusion}

Recent debate points to uncertainties over the future form of medicine reviews in the $\mathrm{UK}^{73,74}$. It will benefit the health of the population if decisions about these and other commissioned pharmacy services are informed by high quality evidence. Despite finding much scope for concern about the conduct of MURs and the NMS, evidence from this review indicates also scope for re-alignment of MURs and the NMS (or their future iterations) with the core values and skillsets espoused in the professional standards for patient-centred care. A recent Cochrane review of pharmacy services for non-hospitalised patients contained little data directly relevant to this review, and emphasised the heterogeneity of data in similar ways to earlier reviews ${ }^{75}$. It also drew attention to the potential for role substitution and anticipated cost savings when health systems broaden the expectations being placed on pharmacists. Any sought economic benefits will not be realised, however, unless pharmacists are able to help patients manage their own health. This entails conducting consultations with a focus squarely on the needs and goals of the patient, including addressing concerns presented and the health outcomes valued by patients, as established from patients' experiences of their medicines and conditions, and what they want from the provision of these services. Simple enquiry and exploration to understand what is important to the individual patient are consistent with pharmacist professional values, welcomed by patients, and achievable to deliver within existing consultation frameworks. 
Table 1: Characteristics of RCTs and quasi-experimental studies

\begin{tabular}{|c|c|c|c|c|c|c|}
\hline Study & NMS/MUR & Objective(s) & Design & Sample & $\begin{array}{l}\text { Time } \\
\text { frame }\end{array}$ & Key findings \\
\hline $\begin{array}{l}\text { Elliott et al. } \\
2016^{21}\end{array}$ & NMS & $\begin{array}{l}\text { Examine the effectiveness } \\
\text { of the NMS on medication } \\
\text { adherence compared with } \\
\text { normal practice }\end{array}$ & RCT & $\begin{array}{l}504 \text { patients } \\
\text { in } 46 \\
\text { community } \\
\text { pharmacies }\end{array}$ & $\begin{array}{l}2012- \\
2013\end{array}$ & $\begin{array}{l}\text { A significantly greater proportion of NMS patients were adherent } \\
\text { compared to normal practice ( } 71 \% \text { vs } 61 \%) \text { at } 10 \text { week follow-up. } \\
\text { Adjusted OR for increased adherence was } 1.67 \text { in favour of the } \\
\text { NMS arm. }\end{array}$ \\
\hline $\begin{array}{l}\text { Elliott et al. } \\
2017^{22}\end{array}$ & NMS & $\begin{array}{l}\text { Examine the effectiveness } \\
\text { of the NMS on medication } \\
\text { adherence compared with } \\
\text { normal practice }\end{array}$ & $\mathrm{RCT}$ & $\begin{array}{l}504 \text { patients } \\
\text { in } 46 \\
\text { community } \\
\text { pharmacies }\end{array}$ & $\begin{array}{l}2012- \\
2013\end{array}$ & $\begin{array}{l}\text { NMS generated a mean of } 0.05 \text { more QALYs per patient, at a mean } \\
\text { reduced cost of }-£ 144 \text {, and a probability of } 0.78 \text { [incremental cost- } \\
\text { effectiveness ratio (ICER) - } £ 3166 \text { per QALY] }\end{array}$ \\
\hline $\begin{array}{l}\text { Elson et al. } \\
2017^{24}\end{array}$ & MUR & $\begin{array}{l}\text { Determine the effects of } \\
\text { targeted hospital } \\
\text { pharmacist counselling or } \\
\text { post-discharge MURs on } \\
\text { patients' knowledge of } \\
\text { medication }\end{array}$ & $\begin{array}{l}\text { Controlled } \\
\text { (non- } \\
\text { randomised) } \\
\text { trial }\end{array}$ & 101 patients & 2013 & $\begin{array}{l}\text { Patients who received pharmacist counselling were more likely to } \\
\text { report being told the purpose of their new medicine and how to } \\
\text { take it. Fewer than half of allocated to receive a MUR actually } \\
\text { received one. }\end{array}$ \\
\hline $\begin{array}{l}\text { Ramsbottom } \\
\text { et al. } 2018^{23}\end{array}$ & MUR & $\begin{array}{l}\text { Evaluate the potential } \\
\text { clinical and economic } \\
\text { impact of community } \\
\text { pharmacists' } \\
\text { interventions during post- } \\
\text { hospital discharge MURs }\end{array}$ & $\begin{array}{l}\text { RCT } \\
\text { feasibility } \\
\text { study }\end{array}$ & 20 patients & $\begin{array}{l}\text { Not } \\
\text { stated }\end{array}$ & $\begin{array}{l}\text { An average of } 2 \text { interventions were instigated per MUR. The most } \\
\text { common was to provide information to improve patient } \\
\text { understanding of their medication and how to use it in the most } \\
\text { effective, convenient and safe way. Indicative cost savings were } \\
\text { found. }\end{array}$ \\
\hline
\end{tabular}


Table 2: Characteristics of secondary data analysis studies

\begin{tabular}{|c|c|c|c|c|c|c|}
\hline Study & NMS/MUR & Objective(s) & Design & Sample & $\begin{array}{l}\text { Time } \\
\text { frame }\end{array}$ & Key findings \\
\hline $\begin{array}{l}\text { Blenkinsopp et } \\
\text { al. } 2008{ }^{25}\end{array}$ & MUR & $\begin{array}{l}\text { Evaluate the first three } \\
\text { years of the MUR service } \\
\text { provision }\end{array}$ & $\begin{array}{l}\text { Longitudinal } \\
\text { analysis of } \\
\text { pharmacy } \\
\text { MUR } \\
\text { provision } \\
\text { records }\end{array}$ & $\begin{array}{l}1,090 \\
\text { pharmacies }\end{array}$ & $\begin{array}{l}2005- \\
2008\end{array}$ & $\begin{array}{l}\text { The number of MURs and pharmacies providing them increased } \\
\text { over successive years. Independents were less likely than multiples } \\
\text { to provide MURs, and those independents that did conducted } \\
\text { fewer. }\end{array}$ \\
\hline $\begin{array}{l}\text { Wells et al. } \\
2014^{26}\end{array}$ & NMS & $\begin{array}{l}\text { Investigate the proportion } \\
\text { of prescription items } \\
\text { eligible for the NMS and if } \\
\text { eligibility is affected by } \\
\text { pharmacies' proximity to } \\
\text { GP practices }\end{array}$ & $\begin{array}{l}\text { Cross } \\
\text { sectional } \\
\text { analysis of } \\
\text { prescription } \\
\text { data }\end{array}$ & $\begin{array}{l}8005 \\
\text { prescription } \\
\text { items }\end{array}$ & 2013 & $\begin{array}{l}0.25 \% \text { of prescription items were eligible for the NMS, lower than } \\
\text { the assumed } 0.5 \% \text {. The opportunity rate for NMS was } 0.21 \% \text { of } \\
\text { items, as some eligible items did not translate into opportunities to } \\
\text { offer the service. GP proximity made no difference. }\end{array}$ \\
\hline $\begin{array}{l}\text { Nazar et al. } \\
2016^{27}\end{array}$ & NMS/MUR & $\begin{array}{l}\text { Evaluate an electronic } \\
\text { patient referral system } \\
\text { from hospital to } \\
\text { community pharmacies }\end{array}$ & $\begin{array}{l}\text { Cross } \\
\text { sectional } \\
\text { analysis of } \\
\text { hospital } \\
\text { referral data }\end{array}$ & 2029 patients & $\begin{array}{l}2014- \\
2015\end{array}$ & $\begin{array}{l}\text { Only } 31 \% \text { of patients received a community pharmacist follow-up } \\
\text { consultation. Most referred patients were over } 60 \text { years of and } \\
\text { referred for a MUR or the NMS. Patients who received a follow-up } \\
\text { consultation had fewer readmissions and shorter hospital stays. }\end{array}$ \\
\hline
\end{tabular}


Table 3: Characteristics of mixed methods studies

\begin{tabular}{|c|c|c|c|c|c|c|}
\hline Study & NMS/MUR & Objective(s) & Design & Sample & $\begin{array}{l}\text { Time } \\
\text { frame }\end{array}$ & Key findings \\
\hline $\begin{array}{l}\text { Blenkinsopp et } \\
\text { al. } 2007^{28}\end{array}$ & MUR & $\begin{array}{l}\text { Measure MUR provision in } \\
\text { first year of } \\
\text { implementation }\end{array}$ & $\begin{array}{l}\text { Postal } \\
\text { survey; cross } \\
\text { sectional } \\
\text { analysis of } \\
\text { pharmacy } \\
\text { records; } \\
\text { interviews }\end{array}$ & $\begin{array}{l}1,072 \\
\text { pharmacies; } \\
29 \text { primary } \\
\text { care } \\
\text { organisations }\end{array}$ & $\begin{array}{l}2005- \\
2006\end{array}$ & $\begin{array}{l}\text { Quantitative: Uptake and spread of MURs was low, and dominated } \\
\text { by multiples. } \\
\text { Qualitative: Relationships between pharmacists and GPs a key } \\
\text { barrier to implementation. }\end{array}$ \\
\hline $\begin{array}{l}\text { Bradley et al. } \\
2008^{29}\end{array}$ & MUR & $\begin{array}{l}\text { Explore and identify the } \\
\text { key determinants } \\
\text { influencing uptake of } \\
\text { MURs }\end{array}$ & $\begin{array}{l}\text { Survey, } \\
\text { interviews } \\
\text { and cross } \\
\text { sectional } \\
\text { analysis of } \\
\text { MUR data }\end{array}$ & $\begin{array}{l}\text { MUR data } \\
\text { from } 9872 \\
\text { pharmacies; } \\
\text { Survey } \\
\text { ( } n=216 \text { ) of } \\
\text { primary care } \\
\text { organisations; } \\
\text { stakeholder } \\
\text { interviews } \\
(n=43)\end{array}$ & $\begin{array}{l}2005- \\
2007\end{array}$ & $\begin{array}{l}\text { Quantitative: Rates of MURs by multiples were almost twice that of } \\
\text { independents. Survey respondents perceived lack of GP support to } \\
\text { be the greatest barrier to MUR implementation. } \\
\text { Qualitative: Organisational pressure within multiple pharmacies was } \\
\text { identified as driving MUR activity. }\end{array}$ \\
\hline $\begin{array}{l}\text { Portlock et al. } \\
2009^{32}\end{array}$ & MUR & $\begin{array}{l}\text { Evaluate MUR } \\
\text { interventions for asthma }\end{array}$ & $\begin{array}{l}\text { MUR } \\
\text { outcome } \\
\text { audit; } \\
\text { Feedback } \\
\text { forms }\end{array}$ & $\begin{array}{l}965 \text { patients; } \\
28 \\
\text { pharmacists; } \\
15 \text { GPs }\end{array}$ & 2007 & $\begin{array}{l}\text { Quantitative: MUR numbers varied markedly between pharmacies. } \\
\text { Adherence was greater among patients who had received a GP } \\
\text { review in the past year. MURs increased patient knowledge about } \\
\text { their condition and treatment. } \\
\text { Qualitative: Patient feedback was positive about overall impression } \\
\text { of the service, privacy, demonstration of inhalers, explanations of } \\
\text { medication and convenience. }\end{array}$ \\
\hline
\end{tabular}


Brown et al. MUR

$2014^{31}$

Assess the impact of the

healthy living pharmacy

(HLP) framework on

service provision and staff

engagement

Identify factors associated

with variation in the

volume of services

delivered by community

pharmacies
Cross

sectional

analysis of

pharmacy

records;

interviews

Longitudinal $\quad 10,454$

analysis of

national

MUR data;

postal

survey
17 HLPs and

19 non-HLPs;

38 community

pharmacy

staff, including

25

pharmacists

pharmacies;

284 pharmacy

representative

2011- Quantitative: Significantly more clients per pharmacy were seen in

2012 HLPs than non-HLPs for MURs (medians: 29 vs 11).

Qualitative: None relevant to MURs.

$2011-$

2016

independents), greater dispensing volume, and lower disease

prevalence. Survey responses supported these findings, with MUR

volume also associated with weekly opening hours and lower

asthma prevalence. 
Table 4: Characteristics of surveys

\begin{tabular}{|c|c|c|c|c|c|c|}
\hline Study & NMS/MUR & Objective(s) & Design & Sample & $\begin{array}{l}\text { Time } \\
\text { frame }\end{array}$ & Key findings \\
\hline $\begin{array}{l}\text { Wilcock \& } \\
\text { Harding } 2007 \\
36\end{array}$ & MUR & $\begin{array}{l}\text { Explore GPs' perceptions } \\
\text { of MURs }\end{array}$ & $\begin{array}{l}\text { Self- } \\
\text { complete } \\
\text { survey }\end{array}$ & $52 \mathrm{GPs}$ & 2007 & $\begin{array}{l}\text { GPs reported good relationships with community pharmacists, but } \\
\text { had negative views about MURs. Lack of clarity about the purpose } \\
\text { of MURs and concerns about pharmacists advising on clinical rather } \\
\text { than practical issues were raised. }\end{array}$ \\
\hline $\begin{array}{l}\text { Latif \& } \\
\text { Boardman } \\
2008^{43}\end{array}$ & MUR & $\begin{array}{l}\text { Investigate factors that } \\
\text { influence the number of } \\
\text { MURs performed by } \\
\text { community pharmacists } \\
\text { and pharmacists' attitudes } \\
\text { towards the service }\end{array}$ & $\begin{array}{l}\text { Postal } \\
\text { survey }\end{array}$ & $\begin{array}{l}167 \\
\text { community } \\
\text { pharmacists } \\
\text { from one } \\
\text { pharmacy } \\
\text { chain }\end{array}$ & 2006 & $\begin{array}{l}\text { More MURs were performed by store based pharmacists than } \\
\text { locums, and by those with access to a consultation room. Most } \\
\text { respondents felt that MURs would be of benefit to patients, but } \\
\text { reported concerns about GP opinions of the service, and lack of } \\
\text { time and support staff to conduct MURs. }\end{array}$ \\
\hline $\begin{array}{l}\text { James et al. } \\
2008^{57}\end{array}$ & MUR & $\begin{array}{l}\text { Develop criteria for } \\
\text { assessment of MUR } \\
\text { referral documentation }\end{array}$ & Delphi study & $\begin{array}{l}16 \text { Delphi } \\
\text { panellists }\end{array}$ & 2006 & Twenty MUR quality indicators were agreed. \\
\hline $\begin{array}{l}\text { Youssef et al. } \\
2009^{54}\end{array}$ & MUR & $\begin{array}{l}\text { Evaluate MUR workshops } \\
\text { for undergraduate } \\
\text { pharmacy students }\end{array}$ & $\begin{array}{l}\text { Self- } \\
\text { complete } \\
\text { survey }\end{array}$ & $\begin{array}{l}107 \\
\text { undergraduat } \\
\text { e pharmacy } \\
\text { students }\end{array}$ & $\begin{array}{l}\text { Not } \\
\text { stated }\end{array}$ & $\begin{array}{l}\text { Students would value demonstration of well and poorly conducted } \\
\text { MURs, with real life case studies. }\end{array}$ \\
\hline $\begin{array}{l}\text { Harding \& } \\
\text { Wilcock } 2010 \\
55\end{array}$ & MUR & $\begin{array}{l}\text { Explore existing } \\
\text { mechanism to ensure } \\
\text { quality assurance of } \\
\text { medicine use reviews } \\
\text { (MURs), and to identify } \\
\text { those parameters of an } \\
\text { MUR that community } \\
\text { pharmacists consider as } \\
\text { indicators of quality }\end{array}$ & $\begin{array}{l}\text { Postal } \\
\text { survey }\end{array}$ & $\begin{array}{l}50 \text { community } \\
\text { pharmacists }\end{array}$ & 2008 & $\begin{array}{l}\text { Pharmacists exercise their judgement about whether to undertake } \\
\text { a MUR with a patient. Pharmacists shared a common sense of poor } \\
\text { practice, but were less clear about defining a well conducted MUR. }\end{array}$ \\
\hline
\end{tabular}


Youssef et al. $2010^{50}$

MUR

Examine patient benefit

following MURs

Postal

survey

2008

Explore the range of dermatology MURs

undertaken by

pharmacists and their

confidence in dealing with

the provision of advice to

patients.

$\begin{array}{ll}\text { Merks et al. } \quad \text { MUR } & \text { Assess patients' opinion } \\ & \text { about prevalence of } \\ & \text { pharmaceutical services } \\ & \text { available in a community } \\ & \text { pharmacy in a rural area } \\ & \text { and identify appropriate } \\ & \text { action(s) to enhance } \\ & \text { patients' awareness of } \\ & \text { pharmaceutical services in } \\ & \text { rural areas. }\end{array}$

Rodgers et al. NMS/MUR Compare the perceptions

$2016^{48}$ complete

Survey

Street and

postal

surveys
870

community

pharmacists

103 patients

1000 public

respondents;

341

pharmacists of pharmacists and the general public on MURs and the NMS.
Two thirds of patients thought they learnt more about their medicines after the MUR, 58\% thought the MUR increased awareness of medicine side effects, and $83 \%$ thought the MUR improved their compliance. Older patients perceived more benefit.

Not Over $40 \%$ of pharmacists undertook dermatology MURs and rated stated themselves as confident in this role. More MURs were conducted by pharmacists employed by multiples.

Awareness of expanded pharmaceutical services was poor; MUR was the only advanced service used (by $13 \%$ of respondents), primarily by men. 
Twigg et al.

$2016^{64}$

MUR

Cheema et al. NMS $2017^{60}$

\begin{tabular}{|c|c|c|c|}
\hline $\begin{array}{l}\text { Hamedi et al. } \\
2017^{58}\end{array}$ & NMS & $\begin{array}{l}\text { Assess community } \\
\text { pharmacists' practice, } \\
\text { knowledge and } \\
\text { confidence in supporting } \\
\text { patients' adherence as } \\
\text { part of the NMS for } \\
\text { patients on Oral Anti- } \\
\text { Coagulants for stroke } \\
\text { prevention in Atrial } \\
\text { Fibrillation }\end{array}$ & $\begin{array}{l}\text { On-line } \\
\text { survey }\end{array}$ \\
\hline $\begin{array}{l}\text { Hindi et al. } \\
2017^{49}\end{array}$ & MUR & $\begin{array}{l}\text { Develop, pilot, and utilize } \\
\text { a MUR patient satisfaction } \\
\text { questionnaire }\end{array}$ & $\begin{array}{l}\text { Postal } \\
\text { survey }\end{array}$ \\
\hline
\end{tabular}

Assess the impact of the NMS on medication use by patients starting a new medication for a long-

term medical condition.

completed

es
Examine information

needs and reported

adherence of patients

who received a

community pharmacy

advanced service.

232 patients

from 4

community

pharmacies

questionnair

257 patients

$2014-$
2015

505 patients

2016

Not

stated medicines, particularly about potential medication problems.

Satisfaction with information about medicines and adherence were significantly greater among patients who had received an advanced service, such as a MUR.

On the first NMS assessment, 82 patients reported drug-related problems of whom 58 received pharmacists' advice. At follow up 39 $(67 \%)$ of these 58 patients reported resolution of problems

compared to $17 \%$ of the patients who did not receive pharmacists' advice (OR=10.2).

Priorities during the NMS consultation were to discuss actions to take when bleeding occurs and supporting adherence. Pharmacists were more confident in their knowledge, skills and access to resources for Vitamin-K Antagonists than for new oral anticoagulants.

Patients showed a high degree of overall satisfaction with MURs, even if initially reluctant to take part in one. 
Rutter et al.

$2017^{44}$

MUR

Investigate the

perspective of community survey

pharmacists on the

usefulness of and

suitability of MUR

referrals from hospital.

\section{Aston et a}

$2018^{46}$
NMS/MUR Determine whether

community pharmacists

undertake MUR or NMS

with children/their carers

and identify the type of

medication-related

experiences presented to

them when a child is

taking long-term

medication
Postal

19 community Not

pharmacists stated

Postal

survey

76 community

pharmacists
Barriers to implementation were failure or inability of patients to

attend the pharmacy. Community pharmacists' views of the

service were positive, but felt further medications information would be useful for referrals.

MUR and NMS utilised by community pharmacists for

children/carers. Presentations were for non-adherence including

stopping medication and changing dose. Pharmacists were directly asked about dose, administration and adverse effects. 
Table 5: Characteristics of qualitative studies

\begin{tabular}{|c|c|c|c|c|c|c|}
\hline Study & NMS/MUR & Objective(s) & Design & Sample & $\begin{array}{l}\text { Time } \\
\text { frame }\end{array}$ & Key findings \\
\hline $\begin{array}{l}\text { Urban et al. } \\
2008^{39}\end{array}$ & MUR & $\begin{array}{l}\text { Explore community } \\
\text { pharmacists' } \\
\text { experience of } \\
\text { conducting MJRs }\end{array}$ & Interviews & $\begin{array}{l}21 \text { community } \\
\text { pharmacists }\end{array}$ & $\begin{array}{l}\text { Not } \\
\text { stated }\end{array}$ & $\begin{array}{l}\text { Uncertainty about the best ways to select and recruit patients for } \\
\text { MURs. Perception that MURs improve patient understanding and use } \\
\text { of their medications. Perception that GPs have doubts about the } \\
\text { value of MURs. }\end{array}$ \\
\hline $\begin{array}{l}\text { McDonald et } \\
\text { al. } 2010^{42}\end{array}$ & MUR & $\begin{array}{l}\text { Explore community } \\
\text { pharmacists' } \\
\text { reactions to the } \\
\text { introduction of } \\
\text { MURs }\end{array}$ & Interviews & $\begin{array}{l}49 \text { community } \\
\text { pharmacists }\end{array}$ & $\begin{array}{l}2007- \\
2008\end{array}$ & $\begin{array}{l}\text { Support for MURs was high, although workload pressures hindered } \\
\text { pharmacists ability to undertaken them. Some pharmacists (from } \\
\text { multiples) felt under pressure to meet MUR targets. }\end{array}$ \\
\hline $\begin{array}{l}\text { van den Berg } \\
\text { M \& Donyai } \\
2010^{53}\end{array}$ & MUR & $\begin{array}{l}\text { Investigate the } \\
\text { depiction of the } \\
\text { patient-pharmacist } \\
\text { power relationship } \\
\text { within MUR patient } \\
\text { information leaflets }\end{array}$ & $\begin{array}{l}\text { Discourse } \\
\text { analysis }\end{array}$ & 11 leaflets & 2006 & $\begin{array}{l}\text { A variety of terminology was used to describe MURs, with the } \\
\text { intended cooperative nature of the service not fully described. }\end{array}$ \\
\hline $\begin{array}{l}\text { Latif et al. } \\
2011^{17}\end{array}$ & MUR & $\begin{array}{l}\text { Understand the } \\
\text { contribution of } \\
\text { MURs to } \\
\text { counselling practice }\end{array}$ & $\begin{array}{l}\text { Observations, } \\
\text { patient and } \\
\text { pharmacy staff } \\
\text { interviews }\end{array}$ & $\begin{array}{l}54 \text { MURs, } 34 \\
\text { patient } \\
\text { interviews, } 17 \\
\text { staff interviews, } \\
\text { from } 2 \\
\text { community } \\
\text { pharmacies }\end{array}$ & $\begin{array}{l}2008- \\
2009\end{array}$ & $\begin{array}{l}\text { MURs were short, with pharmacists asking mainly closed questions. } \\
\text { Patients rarely asked questions. Knowledge and use of medicines was } \\
\text { largely unaffected. Practical factors hindered MUR implementation. }\end{array}$ \\
\hline
\end{tabular}


Latif et al.

$2013^{33}$

MUR

Examine patient

perspectives of

MURs and GP-

pharmacist

collaboration

\begin{abstract}
Latif et al.
$2013^{34}$
\end{abstract}

MUR

Describe patients'

perspective of the

MUR service and

what value that

they derive from it.

\begin{tabular}{|c|c|c|}
\hline $\begin{array}{l}\text { Latif et al. } \\
2013^{35}\end{array}$ & MUR & $\begin{array}{l}\text { Explore the impact } \\
\text { and consequences } \\
\text { of MURs on } \\
\text { pharmacy support- } \\
\text { staff }\end{array}$ \\
\hline
\end{tabular}

van den Berg

MUR

M \& Donyai

$2014^{51}$

staff

Develop a patient

satisfaction

conceptual

\section{Observations}

and interviews

54 MURs, 34

patient

2008-

interviews, 17

staff interviews,

from 2

community

pharmacies

\section{Observations}

and interviews

34 patients from

2 community

pharmacies

2008-

2009

Observations

and interviews

5 community

pharmacists; 12

2008-

support staff

framework
Observations

and interviews

7 MURs and 15

patient

interviews
Patients reported positive views about MURs. Little evidence of pharmacists and GPs working collaboratively. MURs conducted in isolation from other aspects of patient care. Potential for MURs to cause tensions with GPs.

Patients were comfortable speaking with the pharmacist and the MUR provided reassurance about their medicines. The purpose of MURs was unclear to patients and did not improve their medicine knowledge or use.

Some support-staff felt frustrated when left to explain to patients why the pharmacist was not available when carrying out an MUR

Five themes identified: relationships with healthcare providers; attitudes towards healthcare providers; patients' experience of health, healthcare and medicines; patients' views of the MUR service; the logistics of the MUR service. 
Wells et al.

pharmacists' views and experiences of the NMS prior to

implementation to and barriers to its success

Lucas \&

Blenkinsopp

$2015^{38}$

Latif et al.

$2016^{37}$

NMS

Waring et al.

NMS

$2016^{59}$

pharmacists'

Explore NMS

implementation

\section{Explore changing}

dynamics of identify facilitators

Focus groups

and interviews

15 community

pharmacists; 5

superintendent

pharmacists

14 community

pharmacists

experiences and

perceptions of NMS

Observations

and interviews

7 community

pharmacists and

$11 \mathrm{GPs}$

pharmacist-patient

power after

introduction of the

NMS
Observations and interviews
20 patients and

27 community

pharmacists
2011

Views of the NMS were positive. Potential barriers included lack of interest/awareness by GPs and the payment structure, speed of implementation, and absence of some support materials.
2012

Pharmacists perceived the NMS as beneficial, providing additional advice and reassurance to patients. The opportunity to utilise their professional expertise was welcomed, but different levels of collaborative working with GPs were reported.

Pharmacists were pragmatic, simplifying, and adapting the NMS to facilitate delivery. Pharmacists held positive views about the value of the NMS, but reported not identifying problems with medicines.

Poor pharmacist-GP relationships impeded implementation.

2012-

NMS extends the 'pharmacy gaze' to further aspects of patients' health and lifestyle, beyond dispensing and advice giving, and results in greater complexity in pharmacist-patient relational power. 
Latif et al.

2018

MUR

Explore the

medicine needs of

Workshops and

interviews

patients from

marginalised

communities and

how services could

better meet their

requirements

$\begin{array}{lll}\begin{array}{l}\text { Latif et al. NMS } \\ 2018^{52}\end{array} & \begin{array}{l}\text { Examine } \\ \text { implementation of } \\ \text { the NMS }\end{array} & \begin{array}{l}\text { Observation } \\ \text { and interviews }\end{array}\end{array}$

Workshops: 23

patients; 24

pharmacy

professionals

Interviews: 10

patients; 10

pharmacy staff

Observation: 20

patients

Interviews: 35

patients; 47

community

pharmacists; 11

GPs
2016 problems with adherence. Experiences of pharmacy services were variable, with many experiencing discrimination or disadvantage.

2012-

2013

Patients were generally unaware of the NMS. Patients tended to report having no problems with their medicines or to adopt their own strategies for dealing with them. Consultations were generally passive and focussed on how patients were 'getting on' with their medication. 
Figure 1: PRISMA flow chart of search strategy and article selection
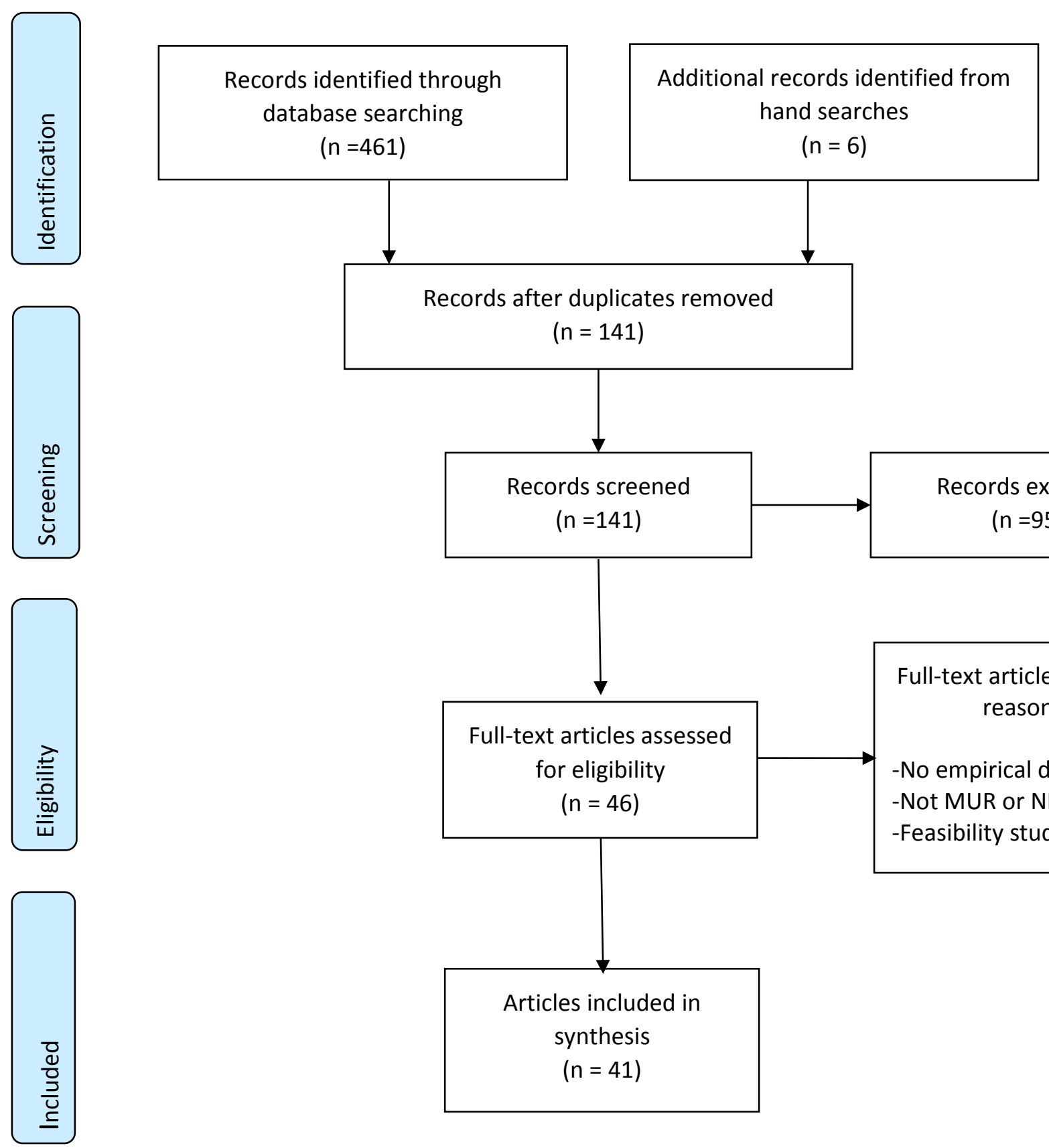

Records after duplicates removed

$$
\text { ( } n=141 \text { ) }
$$
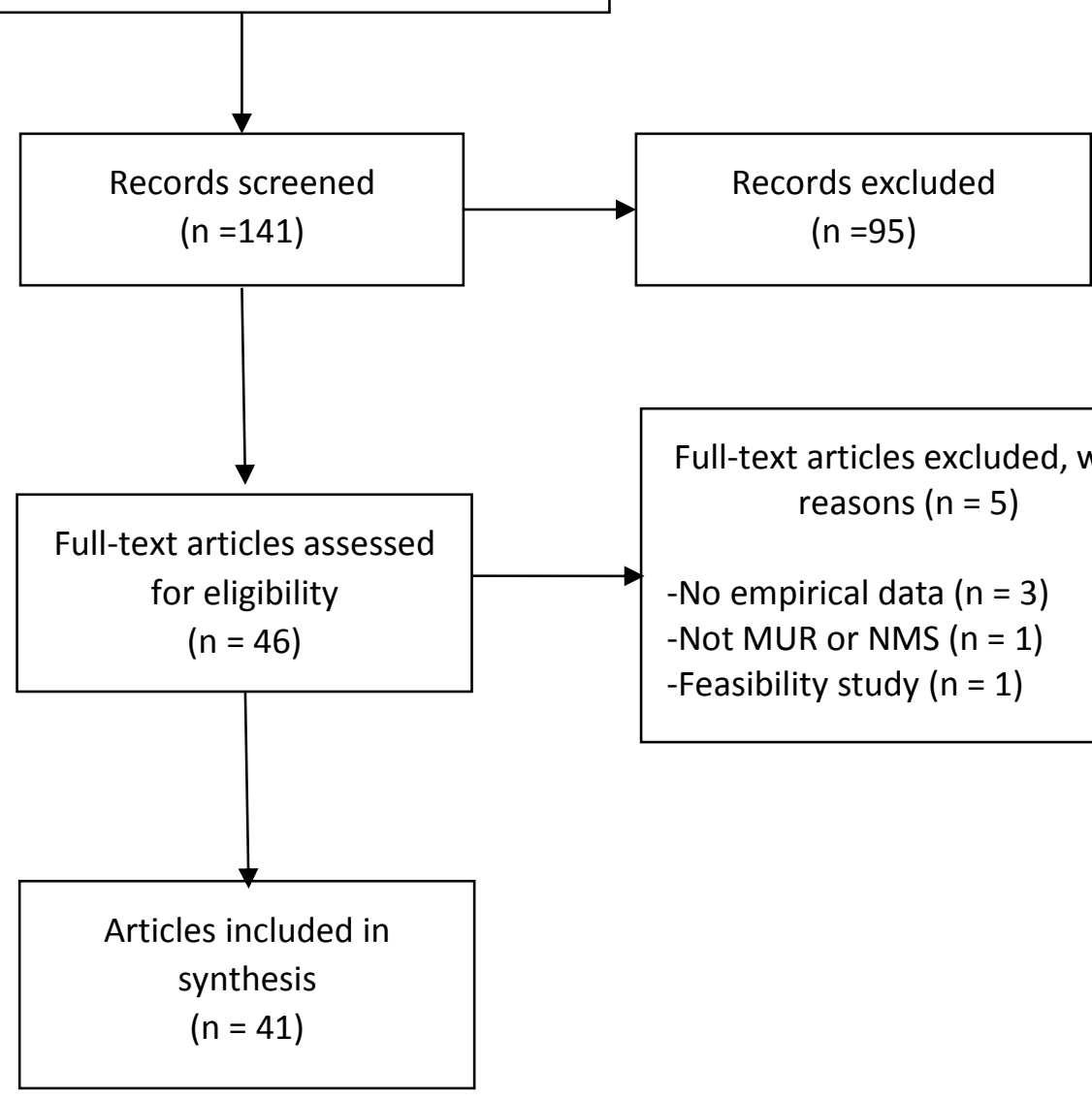

Full-text articles excluded, with reasons $(n=5)$

-No empirical data $(n=3)$

-Not MUR or NMS $(n=1)$

-Feasibility study $(n=1)$ 


\section{REFERENCES}

1. Blenkinsopp A, Bond C, Raynor DK. Medication reviews. Br J Clin Pharm. 2012;74:573-580.

2. Jokanovic N, Tan EC, Sudhakaran S, et al. Pharmacist-led medication review in community settings: An overview of systematic reviews. Res Social Adm Pharm. 2017;13:661-685.

3. Hatah E, Braund R, Tordoff J, Duffull SB. A systematic review and meta-analysis of pharmacist-led fee-for-services medication review. Br J Clin Pharmacol. 2014;77:102-115.

4. Viswanathan M, Kahwati LC, Golin CE, et al. Medication therapy management interventions in outpatient settings: A systematic review and meta-analysis. JAMA Internal Medicine. 2015;175:76-87.

5. Jokanovic N, Tan ECK, van den Bosch D, Kirkpatrick CM, Dooley MJ, Bell JS. Clinical medication review in Australia: A systematic review. Res Social Adm Pharm. 2016;12:384418.

6. Department of Health and Social Care. Pharmaceutical Services (Advanced and Enhanced Services) (England) Directions 2013: Department of Health and Social Care; 2013.

7. Pharmaceutical Services Negotiating Committee. Advanced Service Payments; https://psnc.org.uk/funding-and-statistics/funding-distribution/advanced-servicepayments/; Accessed 03.02.19

8. Pharmaceutical Services Negotiating Committee. MURs: the basics; https://psnc.org.uk/services-commissioning/advanced-services/murs/murs-the-basics/; Accessed 05.07.18.

9. Pharmaceutical Services Negotiatinig Committee. New Medicine Service (NMS); https://psnc.org.uk/services-commissioning/advanced-services/nms/; Accessed 05.07.18.

10. Hall NJ, Donovan G, Wilkes S. A qualitative synthesis of pharmacist, other health professional and lay perspectives on the role of community pharmacy in facilitating care for people with long-term conditions. Res Social Adm Pharm. 2018.

11. Anderson C, Blenkinsopp A, Armstrong M. Feedback from community pharmacy users on the contribution of community pharmacy to improving public's health: a systematic review of the peer reviewed and non-peer reviewed literature 1990-2002. Health Expect. 2004;7:191202.

12. Blenkinsopp A, Anderson C, Armstrong M. Systematic review of the effectiveness of community pharmacy-based interventions to reduce risk behaviours and risk factors for coronary heart disease. J Public Health Med. 2003;25:144-153.

13. Brown D, Portlock J, Rutter $P$, Nazar Z. From community pharmacy to healthy living pharmacy: positive early experiences from Portsmouth, England. Res Social Adm Pharm. 2014;10:72-87.

14. NHS England. NHS: Five year forward view2014.

15. Brown TJ, Todd A, O'Malley C, et al. Community pharmacy-delivered interventions for public health priorities: a systematic review of interventions for alcohol reduction, smoking cessation and weight management, including meta-analysis for smoking cessation. $B M J$ Open. 2016;6:e009828.

16. Eades CE, Ferguson JS, O'Carroll RE. Public health in community pharmacy: A systematic review of pharmacist and consumer views. BMC Public Health. 2011;11:582.

17. Latif A, Pollock K, Boardman HF. The contribution of the Medicines Use Review (MUR) consultation to counseling practice in community pharmacies. Patient Educ Couns. 2011;83:336-344.

18. General Pharmaceutical Council. Standards for pharmacy professionals. London: General Pharmaceutical Council; 2017.

19. Abdel-Tawab R, James DH, Fichtinger A, Clatworthy J, Horne R, Davies G. Development and validation of the Medication-Related Consultation Framework (MRCF). Patient Educ Couns. 2011;83:451-457. 
20. Centre for Pharmacy Postgraduate Education. Conusltation skills for pharmacy practice: taking a patient-centred approach. Manchester: CPPE; 2014.

21. Elliott RA, Boyd MJ, Salema NE, et al. Supporting adherence for people starting a new medication for a long-term condition through community pharmacies: A pragmatic randomised controlled trial of the New Medicine Service. BMJ Qual Saf. 2016;25:747-758.

22. Elliott RA, Tanajewski L, Gkountouras G, et al. Cost Effectiveness of Support for People Starting a New Medication for a Long-Term Condition Through Community Pharmacies: An Economic Evaluation of the New Medicine Service (NMS) Compared with Normal Practice. PharmacoEconomics. 2017;35:1237-1255.

23. Ramsbottom $H$, Rutter $P$, Fitzpatrick R. Post discharge medicines use review (dMUR) service for older patients: Cost-savings from community pharmacist interventions. Res Social Adm Pharm. 2018;14:203-206.

24. Elson R, Cook H, Blenkinsopp A. Patients' knowledge of new medicines after discharge from hospital: What are the effects of hospital-based discharge counseling and community-based medicines use reviews (MURs)? Res Social Adm Pharm. 2017;13:628-633.

25. Blenkinsopp A, Bond C, Celino G, Inch J, Gray N. Medicines use review: Adoption and spread of a service innovation. Int J Pharm Pract. 2008;16:271-276.

26. Wells KM, Boyd MJ, Thornley T, Boardman HF. What proportion of prescription items dispensed in community pharmacies are eligible for the New Medicine Service? BMC Health Serv Res. 2014;14:115.

27. Nazar $\mathrm{H}$, Brice $\mathrm{S}$, Akhter $\mathrm{N}$, et al. New transfer of care initiative of electronic referral from hospital to community pharmacy in England: a formative service evaluation. BMJ open. 2016;6:e012532.

28. Blenkinsopp A, Celino G, bond C, Inch J. Medicines use reviews: the first year of a new community pharmacy service. Pharm J. 2007;278:218-223.

29. Bradley F, Wagner AC, Elvey R, Noyce PR, Ashcroft DM. Determinants of the uptake of medicines use reviews (MURs) by community pharmacies in England: A multi-method study. Health Policy. 2008;88:258-268.

30. Hann M, Schafheutle El, Bradley F, et al. Organisational and extraorganisational determinants of volume of service delivery by English community pharmacies: a crosssectional survey and secondary data analysis. BMJ Open. 2017;7.

31. Brown D, Portlock J, Rutter P, Nazar Z. From community pharmacy to healthy living pharmacy: Positive early experiences from Portsmouth, England. Res Social Adm Pharm. 2014;10:72-87.

32. Portlock J, Holden M, Patel S. A community pharmacy asthma MUR project in Hampshire and the Isle of Wight. Pharm J. 2009;282:109-112.

33. Latif A, Pollock K, Boardman HF. Medicines use reviews: a potential resource or lost opportunity for general practice? BMC family practice. 2013;14:57.

34. Latif A, Boardman HF, Pollock K. Understanding the patient perspective of the English community pharmacy Medicines Use Review (MUR). Res Social Adm Pharm. 2013;9:949-957.

35. Latif $A$, Boardman HF, Pollock K. A qualitative study exploring the impact and consequence of the medicines use review service on pharmacy support-staff. Pharm Pract. 2013;11:118124.

36. Wilcock M, Harding G. General practitioners' perceptions of medicines use reviews by pharmacists. Pharm J. 2007;279:501-503.

37. Latif A, Waring J, Watmough D, et al. Examination of England's New Medicine Service (NMS) of complex health care interventions in community pharmacy. Res Social Adm Pharm. 2016;12:966-989.

38. Lucas B, Blenkinsopp A. Community pharmacists' experience and perceptions of the New Medicines Service (NMS). Int J Pharm Pract. 2015;23:399-406. 
39. Urban R, Rivers P, Morgan J. Perceptions of medicines use reviews: the views of community pharmacists within a West Yorkshire primary care Trust. Pharm J. 2008;281:303-305.

40. Wells KM, Thornley T, Boyd MJ, Boardman HF. Views and experiences of community pharmacists and superintendent pharmacists regarding the New Medicine Service in England prior to implementation. Res Social Adm Pharm. 2014;10:58-71.

41. Tucker $R$. The medicines use review in patients with chronic skin diseases: are pharmacists doing them and how confident are they? Int J Pharm Pract. 2013;21:202-204.

42. McDonald R, Cheraghi-Sohi S, Sanders $C$, Ashcroft D. Professional status in a changing world: The case of medicines use reviews in English community pharmacy. Soc Sci Med. 2010;71:451-458.

43. Latif A, Boardman H. Community pharmacists' attitudes towards medicines use reviews and factors affecting the numbers performed. Pharm World Sci. 2008;30:536-543.

44. Rutter $\mathrm{P}$, Ramsbottom H, Fitzpatrick R. Community pharmacist perceptions of delivering post-hospital discharge Medicines Use Reviews for elderly patients. Int J Clin Pharm. 2017;39:33-36.

45. Merks $P$, Swieczkowski D, Jaguszewski MJ. Patients' perception of pharmaceutical services available in a community pharmacy among patients living in a rural area of the United Kingdom. Pharm Pract. 2016;14:774.

46. Aston J, Wilson KA, Terry DRP. Children/young people taking long-term medication: a survey of community pharmacists' experiences in England. Int J Pharm Pract. 2018;26:104-110.

47. Latif A, Tariq S, Abbasi N, Mandane B. Giving Voice to the Medically Under-Served: A Qualitative Co-Production Approach to Explore Patient Medicine Experiences and Improve Services to Marginalized Communities. Pharmacy (Basel, Switzerland). 2018;6.

48. Rodgers RM, Gammie SM, Loo RL, Corlett SA, Krska J. Comparison of pharmacist and public views and experiences of community pharmacy medicines-related services in England. Patient Prefer Adher. 2016;10:1749-1758.

49. Hindi A, Parkhurst C, Rashidi Y, Ho SY, Patel N, Donyai P. Development and utilization of the Medicines Use Review patient satisfaction questionnaire. Patient Prefer Adherence. 2017;11:1797-1806.

50. Youssef $S$, Hussain $S$, Upton D. Do patients perceive any benefit from medicines use reviews offered to them in community pharmacies? Pharm J. 2010;284:165-166.

51. Van Den Berg M, Donyai P. A conceptual framework of patient satisfaction with a pharmacy adherence service. Int J Clin Pharm. 2014;36:182-191.

52. Latif A, Waring J, Watmough D, Boyd MJ, Elliott RA. 'I expected just to walk in, get my tablets and then walk out': on framing new community pharmacy services in the English healthcare system. Sociology of health \& illness. 2018;40:1019-1036.

53. van den Berg M, Donyai P. How was patient empowerment portrayed in information leaflets describing the community pharmacy Medicines Use Review service in the UK? Patient Educ Couns. 2010;80:274-276.

54. Youssef $S$, Aspinall V, Upton D. Medicines use review workshops for pharmacy undergraduate students. Pharm J. 2009;283:221-222.

55. Harding G, Wilcock M. Community pharmacists' perceptions of medicines use reviews and quality assurance by peer review. Pharm World Sci. 2010;32:381-385.

56. van den Berg M, Donyai P. A conceptual framework of patient satisfaction with a pharmacy adherence service. Int J Clin Pharm. 2014;36:182-191.

57. James $\mathrm{DH}$, Hatten $S$, Roberts $\mathrm{D}$, John $\mathrm{DN}$. Identifying criteria for assessing the quality of medicines use review referral documentation by community pharmacists. Int J Pharm Pract. 2008;16:365-374.

58. Hamedi N, da Costa FA, Horne R, Levitan M, Begley A, Antoniou S. How prepared are pharmacists to support atrial fibrillation patients in adhering to newly prescribed oral anticoagulants? Int J Clin Pharm. 2017;39:1273-1281. 
59. Waring J, Latif A, Boyd M, Barber N, Elliott R. Pastoral power in the community pharmacy: A Foucauldian analysis of services to promote patient adherence to new medicine use. Soc Sci Med. 2016;148:123-130.

60. Cheema $E$, Sutcliffe $P$, Singer DRJ. Community pharmacist-led new medicine service for patients with a long term medical condition: A cross-sectional study. J. Pharm. Pharm. Sci. 2017;9:129-133.

61. Morton K, Pattison H, Langley C, Powell R. A qualitative study of English community pharmacists' experiences of providing lifestyle advice to patients with cardiovascular disease. Res Social Adm Pharm. 2015;11:e17-29.

62. Ogunbayo OJ, Schafheutle EI, Cutts C, Noyce PR. A qualitative study exploring community pharmacists' awareness of, and contribution to, self-care support in the management of long-term conditions in the United Kingdom. Res Social Adm Pharm. 2015;11:859-879.

63. Elvey R, Hassell K, Lewis P, Schafheutle E, Willis S, Harrison S. Patient-centred professionalism in pharmacy: values and behaviours. J Health Org Man. 2015;29:413-430.

64. Twigg MJ, Bhattacharya $D$, Clark $A$, et al. What do patients need to know? A study to assess patients' satisfaction with information about medicines. Int J Pharm Pract. 2016;24:229-236.

65. Latif A. Community pharmacy Medicines Use Review: current challenges. Integrated pharmacy research \& practice. 2018;7:83-92.

66. Centre for Pharmacy Postgraduate Education \& Health Education England. Consultation skills for pharmacy practice: Practice standards for England.

http://www.consultationskillsforpharmacy.com/docs/docc.pdf; Accessed 05.07.18.

67. The Health Foundation. Person-centred care made simple: what everyone should know about person-centred care: The Health Foundation; 2016.

68. Twigg MJ, Wright D, Kirkdale CL, Desborough JA, Thornley T. The UK Pharmacy Care Plan service: Description, recruitment and initial views on a new community pharmacy intervention. PloS one. 2017;12:e0174500.

69. Albasri A, Prinjha S, McManus RJ, Sheppard JP. Hypertension referrals from community pharmacy to general practice: multivariate logistic regression analysis of 131419 patients. $\mathrm{Br}$ J Gen Pract. 2018.

70. Alonso-Perales MDM, Lasheras B, Beitia G, Beltran I, Marcos B, Nunez-Cordoba JM. Barriers to promote cardiovascular health in community pharmacies: a systematic review. Health Promot Int. 2017;32:535-548.

71. NHS England. The NHS belongs to the people: a call to action. London: NHS England; 2013.

72. NHS England. Improving general practice - phase one report. London: NHS England; 2014.

73. Torjesen I. The Murray review: moving in the right direction. Pharm J. 2017;298:Online.

74. Murray R. Community pharmacy clinical services review: NHS England; 2017.

75. de Barra M, Scott CL, Scott NW, et al. Pharmacist services for non-hospitalised patients. Cochrane Database of Systematic Reviews. 2018. 